\title{
eLyra
}

REVISTA DA REDE INTERNACIONAL LYRACOMPOETICS

\section{A Namorada de Óculos e outros desenhos de Luis Manuel Gaspar}

\section{Pedro Meneses}

Estas imagens de Luis Manuel Gaspar são quase todas desenhos a tinta-da-china sobre papel, de pequenas dimensões. O facto de serem a preto e branco foi determinado pelas opções gráficas, quase sempre resultantes de orçamento limitado das editoras que imprimiram os textos. Talvez possamos ler na predominância do tom acinzentado o mundo algo negro, mas não desesperado, não profundamente negro, de Adília Lopes. Em todo o caso, não se trata de um mundo ingénuo, apesar do humor e das incursões paródicas pela literatura juvenil. Luis Manuel Gaspar acompanhou a carreira poética de Adília Lopes no seu início, nos anos 80, tendo ilustrado a sóbria capa do seu segundo livro, O Poeta de Pondichéry (1986). Participou, pois, da deriva editorial de Adília Lopes, autora que fez quase o pleno das editoras subversivas e underground durante os anos 80 e 90 (\& etc, Black Sun Editores, frenesi, Hiena, Mariposa Azual). Em 1987, Luis Manuel Gaspar fará duas ilustrações (uma delas como capa, embora tendo sido cortada devido à falta de espaço) para $A$ Namorada de Óculos, poema publicado como opúsculo pelo Projecto Poros, sediado no Seixal. Um projeto que, segundo Luís Filipe Parrado, não o era bem, antes um nome para a amizade que unia três jovens entre os dezassete e os vinte e poucos anos que viviam no Seixal: João Paulo Baltazar, Paulo Buchinho e o próprio Luís Filipe Parrado. Poros 
materializou a paixão forte e ingénua pela poesia por parte destes jovens, explicou Parrado, que participavam no $D N$-Jovem e organizavam leituras públicas de poetas portugueses (entre os quais Adília Lopes). Foi durante este período dinâmico e entusiasta que surgiu a ideia de publicar seis folhetos chamados Folhas de Pó que consistiam tão-somente em folhas A4 impressas em fundo branco (às vezes, azul) e dobradas em três partes e das quais se faziam 150 exemplares. O último número deste projeto, que avançou "paradisiacamente até à eclosão da rosa", segundo os versos de Adília Lopes, assinalou a mencionada participação da poetisa com Luis Manuel Gaspar. O Decote da Dama de Espadas foi publicado em 1988 pela Imprensa-Nacional Casa da Moeda e o desenho da capa é de Luis Manuel Gaspar. Quase três décadas depois, o ilustrador volta a conceber a capa para uma produção poética de Adília Lopes, no caso o opúsculo Comprimidos, que integrou o n. 20 da revista de poesia e ensaio Telhados de Vidro (2015). Assinale-se, por fim, uma ilustração constante de um livro de Doris Lessing, Gatos e Mais Gatos (tradução de Maria Isabel Barreno, Edições Cotovia, 1995), em que aparece a gata Ofélia de Adília Lopes rodeada de fragmentos de quadros do pintor José Escada (1934-1980), admirado tanto pela poetisa como pelo ilustrador. A obra de José Escada avança de um abstracionismo com traços labirínticos expressionistas (não tão rígidos como a do cinema de Robert Wiene, ressalve-se) para uma arte mais figurativa e pungente de cariz autobiográfico e autorretratista. 


\section{Poeta}

de

Pondichéry

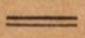

Adilia Lopes

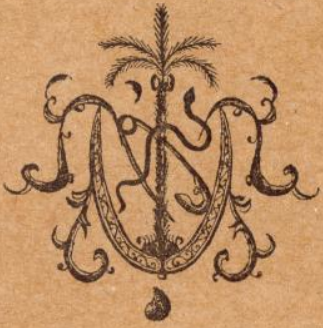

A edição original de $O$ Poeta de Pondichéry (1986) é da responsabilidade das edições frenesi, de Paulo da Costa Domingos (também poeta). A vinheta, para uma capa quase só tipográfica, possui a sobriedade «clássica» em texto e imagem condizente com uma obra em que se refere Diderot. Já consta desta capa a serpente, como símbolo clássico do mal e da metamorfose. 


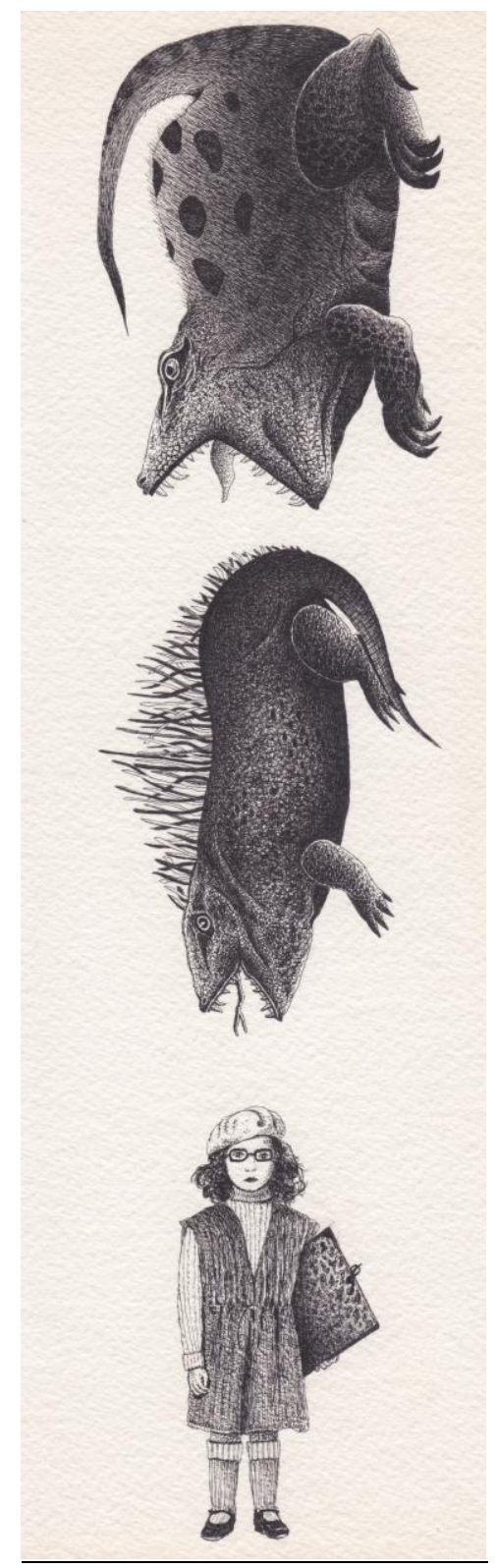

Desenho de capa para o opúsculo A Namorada de Óculos (1987), uma folha A4 azul editada no Seixal pelo Projecto Poros (desenvolvido pelo poeta Luís Filipe Parrado, por João Paulo Baltazar, jornalista e radialista, e por Paulo Buchinho, artista plástico). A boneca de que fala o poema está em vias de ser devorada, surgindo numa atitude entre o estudioso e o observador, o passivo e o delicado. Talvez até um pouco desatenta aos perigos, na circunstância de ter que decidir. Uma interrupção da impassibilidade - a ameaça, a suspensão. Vida estranha e sem consentimento. Uma sensibilidade à maldade de uma observadora lúcida e irónica. O desenho vertical, na folha $\mathrm{A} 4$, teve de abdicar dos monstros por falta de espaço: sorte a deles, que assim não caíram nas mãos da impassível namorada... 


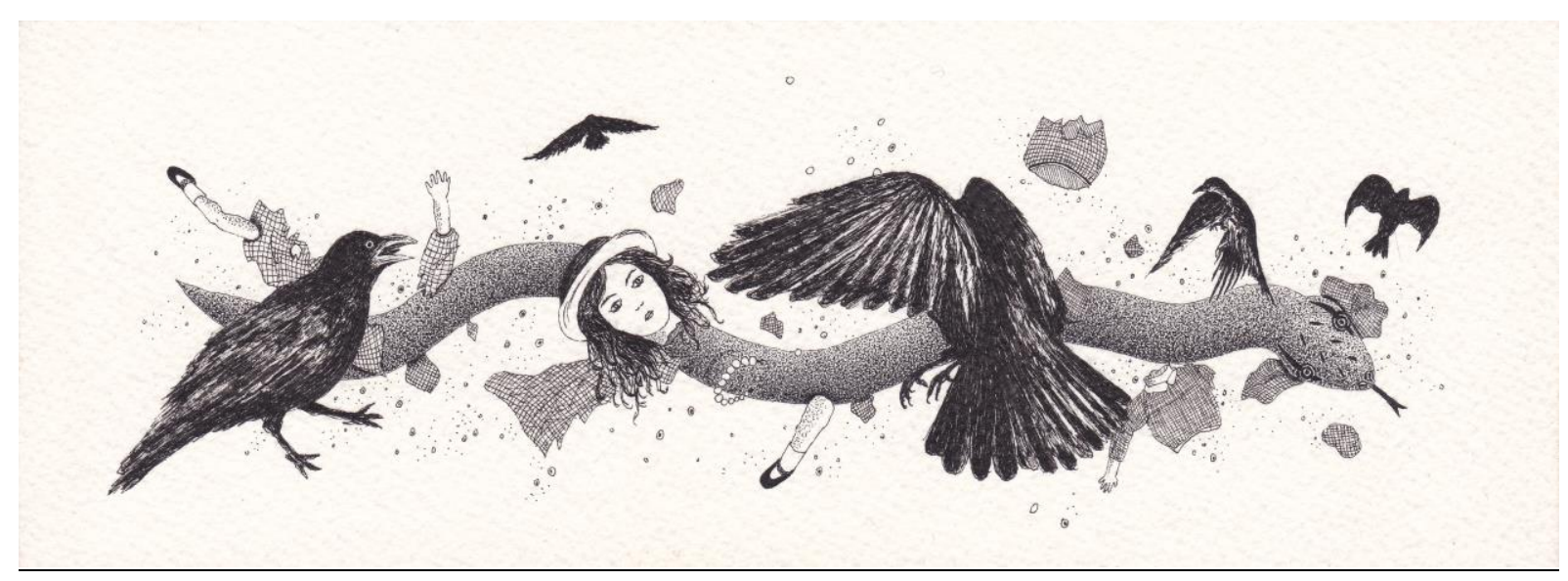

Pertencente ao mesmo opúsculo de 1987, A Namorada de Óculos, a boneca de que fala o poema é atravessada por uma serpente, um monstro, o mal, que não sabemos se nasce de dentro. Virá de fora, como os corvos? Ao mesmo tempo, Adília está com ar impassível, como que imaginada em paralisia em face do mal, em desamparo diante de ataques vindos de todas as direções. Onde começa o caos? Onde acaba? Que linhas o desespero permite traçar, senão as de um movimento em que o devir é inevitabilidade, mas também possibilidade? A um sofrimento pode seguir-se outro sofrimento, compreensão dos engodos da ingenuidade pela boneca, eventualmente uma jovem Adília. O mal é outro nome para o imprevisível, é o desconhecimento da direção para onde supostamente se avança; por fim, é a hipótese do não. 


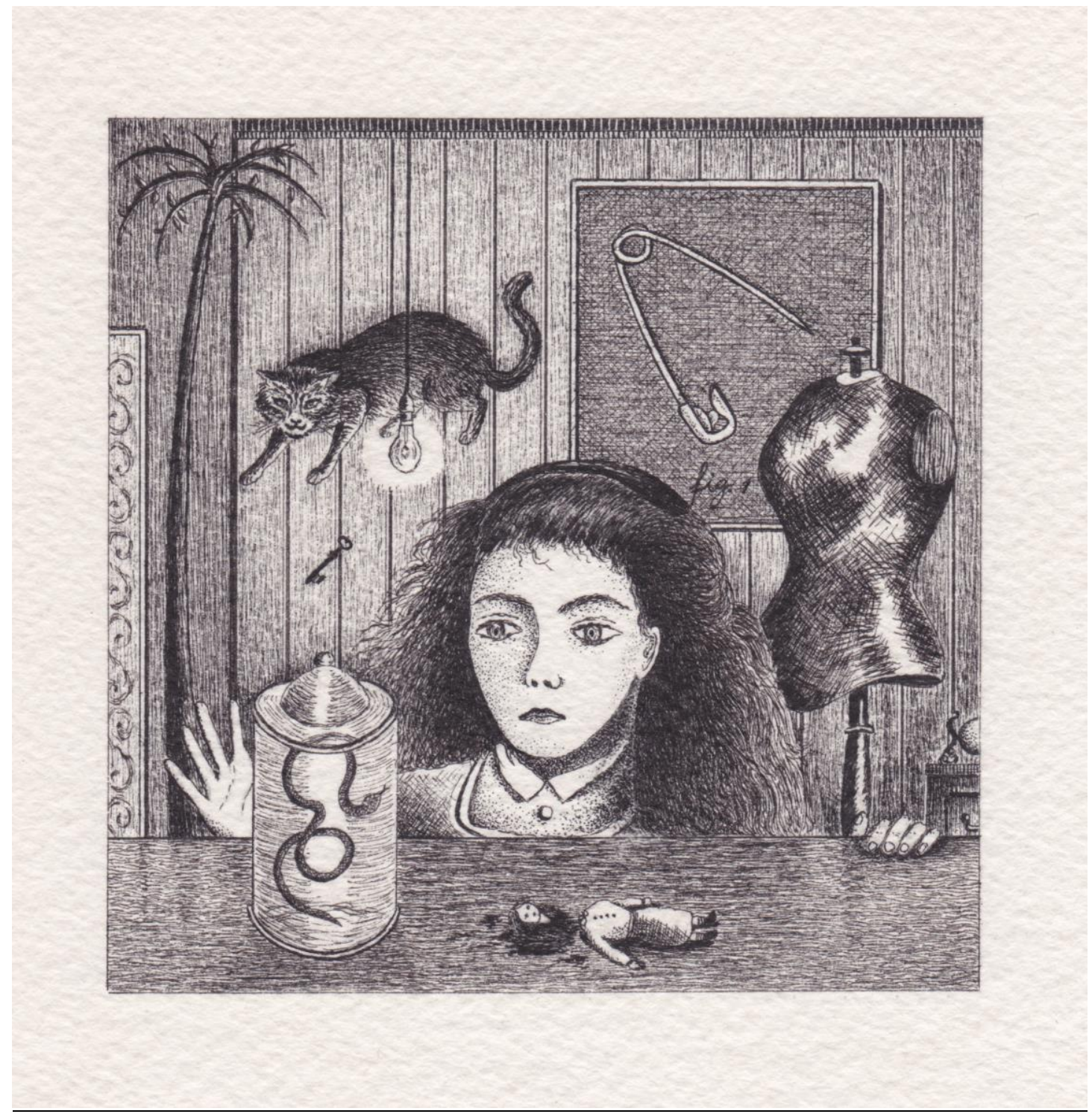

O desenho para capa de O Decote da Dama de Espadas (Romances), volume poético de 1988 publicado em coedição pela Gota de Água e pela Imprensa-Nacional Casa da Moeda, põe em cena uma possível Alice de Lewis Carroll a fazer o papel de Sofia, a personagem da Condessa de Ségur, mas sem autoridade a quem prestar contas. Criança algo introspetiva, num espaço que é laboratório e casa, com uma certa curiosidade pela serpente, no intervalo de uma atividade a que as jovens mulheres eram obrigadas, a costura. No intervalo entre dois aborrecimentos, a criança interessa-se por investigar aquilo que não tem fórmula, o mal. Existe uma distância segura (só é possível a poesia se estivermos a salvo), mas na investigação também há devir. E a possibilidade da ficção, experiência (suspensão, de novo): e se tocasse na serpente? 


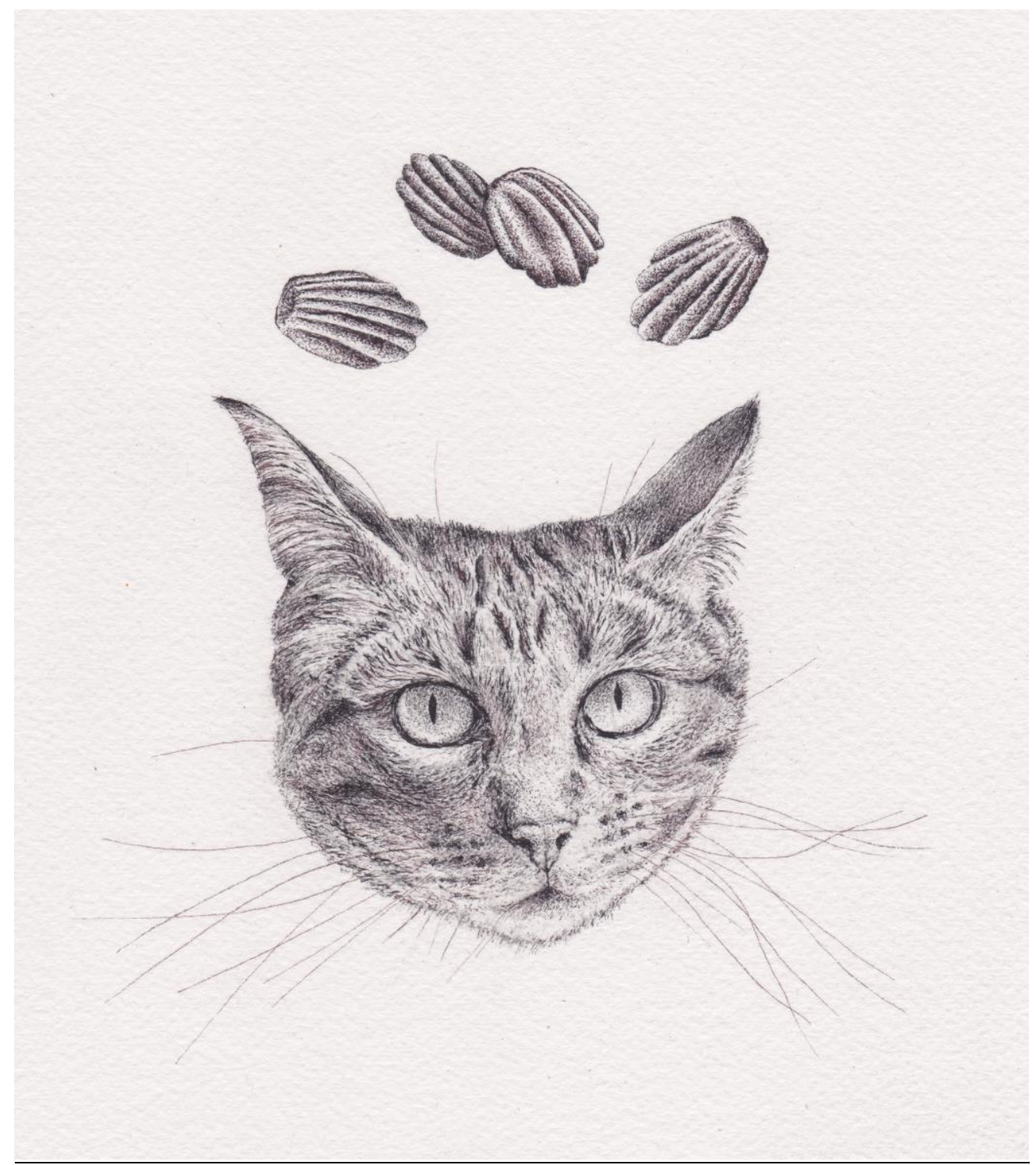

A gata Anita de Daniela Gomes e Luis Manuel Gaspar é a estrela da capa de Comprimidos, opúsculo de 2015 distribuído com o n. ${ }^{\circ} 20$ da revista literária Telhados de Vidro, para além de o ter sido de tantos dos versos adilianos. Por cima de Anita estão bolos, as célebres madalenas de Marcel Proust, descritas num dos fragmentos do livro, que têm realmente a forma de vieiras (conchas) e eram vendidas, segundo informação da autora, na pastelaria Colombo, sita na avenida da República, Lisboa. Comprimidos é um livro breve e aforismático e as conchas podem referir-se não apenas a um universo não apenas íntimo mas também curto e denso. 


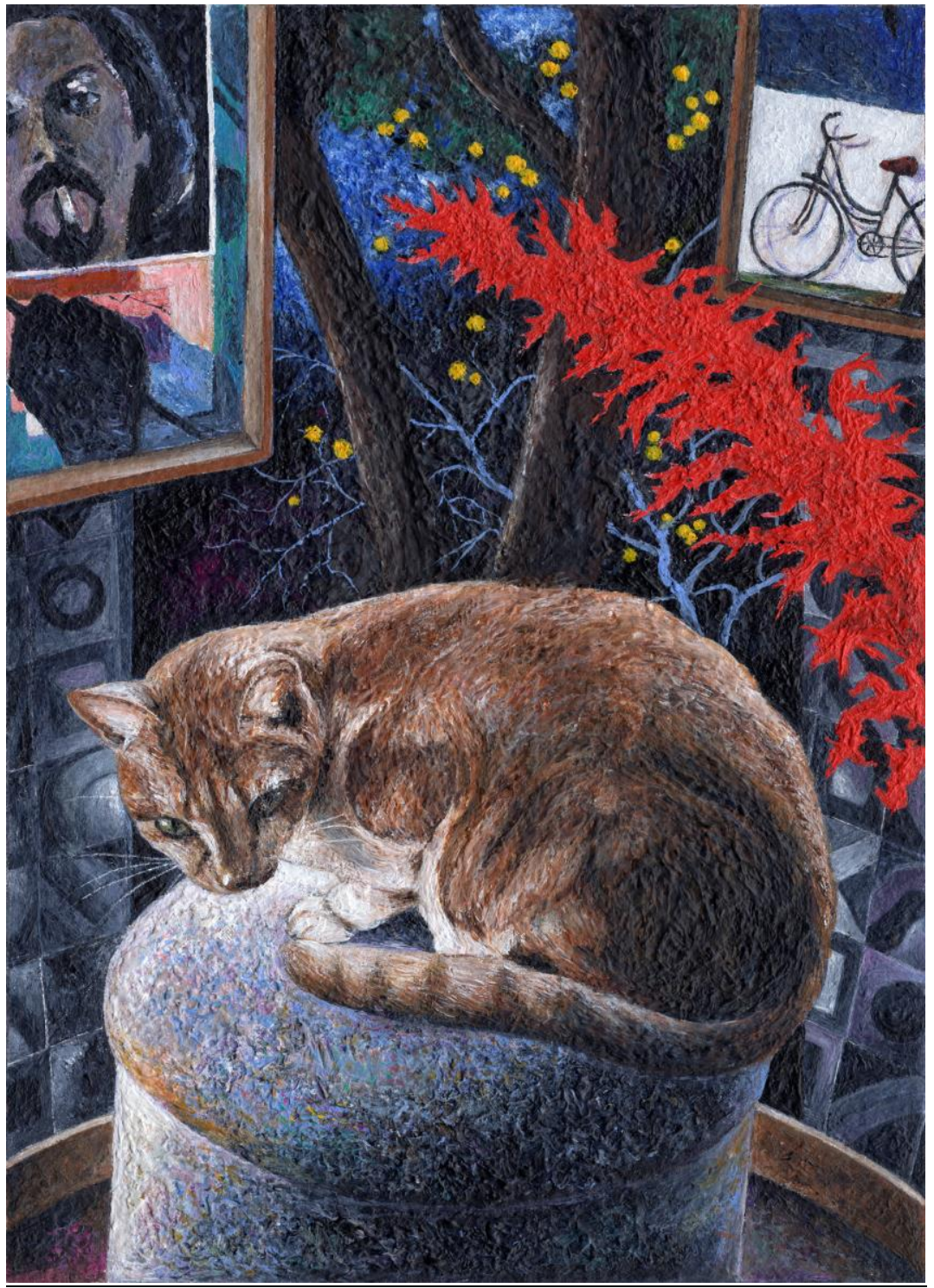

A gata Ofélia de Adília Lopes foi modelo de Luis Manuel Gaspar para ilustração do livro de Doris Lessing, Gatos e Mais Gatos (1995, na edição portuguesa). A poetisa pertencia à troupe dos admiradores da obra de José Escada que visitavam os sítios de deambulação do artista perto da sua casa no Alto de Santo Amaro, espaços frequentes vezes pintados pelo autor. Atenta à atividade de Luis Manuel Gaspar, a gata, relutante, não imerge no sono. Quase abraçando o doce nada (digamos assim), salvaguarda um resto da sua atenção para a possibilidade do perigo. Em suspenso, prepara um movimento ou uma renúncia. É demasiada a cor ali presente, fenda em que acaso e desejo são possíveis. Como na obra de José Escada, não sabemos onde termina a cena representada e começam as citações. Há um jardim por detrás da gata? Ou isso seria um quadro, uma citação entre os vários aspetos do Alto de Santo Amaro representados por Escada? Dando à pata para uma estação interior, o mais mortal dos animais pedala em busca da linha do horizonte, enquanto um animal muito humano quer continuar num mundo com esquinas amolgadas. 